\title{
Study on the Teaching and Scientific Research Team Construction in Applied Colleges by Stage Show "Silk Road Youth"
}

\author{
Haitao Sun \\ Dalian Art College, Dalian, Liaoning, China, 116600
}

Keywords: Repertoire; Teaching Team; Research Team; Construction

\begin{abstract}
With the advancement of applied transformation in colleges and universities, the development of teaching team and scientific research team has also put forward new requirements. Taking the construction of the "Silk Road Youth" teaching team and the team of scientific research and teaching in Dalian Art Institute as an example, this paper analyzes the usefulness of using the teaching of the repertoire and the development of teaching and research team, and puts forward the construction inspiration of universality.
\end{abstract}

\section{The Connotation Requirements of Teaching and Research Team of Application Colleges and Universities}

With the economic development into the new normal, talent supply and demand relations profound changes in the face of profound economic restructuring, industrial upgrading to accelerate the pace of social and cultural construction continue to promote, especially the implementation of innovation-driven development strategy, structural contradictions of higher education more prominent, homogeneous tendency is serious, the employment of graduates is difficult and the problem of low quality of employment has not been effectively alleviated, the application of the lacking of production line, complex, innovative personnel training mechanism has not yet been fully established, personnel training structure and quality is not suited to the economy Structural adjustment and industrial upgrading requirements. All local colleges and universities should adapt to and lead the economic development of the new normal, service innovation drive the development of the overall situation, to promote the transformation of some ordinary undergraduate colleges and universities [1].

In this context, these applied colleges should change their thinking cannot copy the research-oriented colleges and universities to cultivate high-level top-notch innovative professional research-oriented talent development path cannot take vocational skills colleges and universities to cultivate production, construction, service and management first line. The need for skilled personnel development path, but to clear their own positioning, training regional economic development required by the necessary professional theoretical knowledge, strong practical application ability and good professional quality of the application of talent.

The goal and positioning of talents in applied colleges and universities determine the development direction of their teaching team and scientific research team. The teaching team of applied colleges and universities should aim at cultivating the talents needed by the local economy. It consists of a certain number of theoretical teaching teachers and practical teaching teachers (or dual teachers) who have reasonable age, academic qualifications and professional structure. Team leader under the leadership of relying on teamwork mechanism and scientific evaluation mechanism, teaching and research activities, teaching experience exchange seminars, teaching reform, and thus enhance the teaching level and promote the cultivation of applied talents. The research team of applied colleges and universities is a team set up for scientific research and innovation in certain fields. They have similar research objectives and complementary academic background. Under the leadership of team leaders, they rely on team cooperation mechanism and scientific evaluation 
mechanism good at research projects, the development of technology is a strong practical ability to operate, scientific and technological innovation capacity of the team [2].

Application colleges and universities in order to build a good teaching team and research team, to play the maximum performance of both, we must identify the focus and grasp the point. As an applied university, Dalian Art Institute in this area to explore a practical, dual-effect high-energy new road. Arts to cultivate the application of art talent as the goal, through the repertoire of practical teaching, teaching and research will be organic combination, play team spirit and effectiveness, and promote the teaching team and scientific research team building healthy, scientific and efficient development.

\section{The Driven Role of "Silk Road Youth" on the Art of Teaching and Research Team Building}

"Silk Road Youth" is a large-scale repertoire of college on the "one way all the way," a profound interpretation of the idea is the top of the country design ground gas implementation and construction is to cultivate artistic talent from concept to practice important thinking, is the art of teaching reform and school characteristics of the specific show, which is the development of the application of colleges and universities have a significant impact and milestone significance. In recent years, the famous works of "peace trilogy", that is, "soup John" "Sakura Soul" "Peace Ode" won the show success and achieved some winning results. On the basis of the successful experience, but also effort to create "Silk Road youth" to the application of art talent training as the goal, teaching and research throughout the repertoire of the whole process of rehearsal, according to professional characteristics and division of labor, set up the corresponding Teaching team; around the "Silk Road youth" repertoire, the establishment of the professional research projects related to the research team.

"Silk Road Youth" Repertoire Teaching Team Building. Big art set up a "Silk Road youth" repertoire teaching team. Specifically, in the music school, there are teaching team, vocal singing teaching team, musical instrument teaching team, dance performance teaching team; in the clothing college, there are responsible clothing costumes clothing teaching team, responsible for the makeup team ; In the media college, there are script creation teaching team, responsible for the performance of LED design animation teaching team, responsible for the stage behind the scenes interviewed broadcast teaching team, responsible for the repertoire photography, program production photography camera teaching team; college is responsible for props design, production of props teaching team, responsible for the repertoire posters, posters and other design teaching team; in the arts and culture management college, responsible for business pick up, send machine simulation training, front desk etiquette, reception etiquette, reception desk reception, catering service reception and other business reception teaching team and for the reception of foreign guests, friends engaged in English, Japanese, Korean translation of the translation teaching team, and so on.

Each teaching team, composed of 5-9 teachers, as far as possible the formation of the old and middle three generations of reasonable age structure, doctoral graduate teachers, master graduate teachers and other reasonable academic structure, different colleges and universities graduate diversified chemical edge structure, professor, associate professor (By the professional theory teacher + industry experts or double teacher dual-type teacher teaching) teaching content of the scientific settings, and by a high-title teachers (to double the double-type type), the title of the teacher, Teacher is better) as a teaching team leader.

In the "Silk Road youth" repertoire series rehearsal process, the teaching team teachers are both clear division of labor, and mutual communication and cooperation; between the team is also a clear division of labor, but also mutual communication and cooperation. The podium moved from the classroom to the stage, to create a performance as a platform to the stage for the classroom, used to practice, to teach the practice of teaching practice, improve the effectiveness of teaching, so that students can be a good theory with practice , these are simply unable to achieve classroom teaching, and only for practical problems, targeted to explain and solve, in order to make students knowledge application ability, psychological ability, practical ability, artistic perception and expression, spot ability, innovation ability and so are greatly improved. 
In this process, the individual teaching team in the individual ability to have been greatly improved, the cohesion of each teaching team stronger, more standardized management.

Teachers' teaching ability has improved significantly. The team is composed of individuals, only the ability of each individual to enhance the ability of the entire team to mention

First of all, through the "Silk Road Youth" repertoire practice teaching, the teacher's practical teaching ability is improved, the theoretical knowledge into practical application, according to the repertoire of the rehearsal of the specific practical problems for students to answer questions, on-site guidance many professional issues is classroom teaching never involved. Second, through the "Silk Road youth" repertoire practice teaching, teachers will be a variety of teaching methods organic integration, such as teaching methods, teaching methods, case teaching method, heuristic teaching method and discussion teaching method, situational teaching method in one, vivid, specific and efficient to improve the quality of teaching. Once again, through the "Silk Road youth" repertoire practice teaching, teachers will encounter some new problems, resulting in some new ideas both teachers can find their own short board, but also for the future search for tribes, teaching research and reform to provide new thinking and direction.

Teaching team cohesion increased significantly. The cohesion of the teaching team is to play the premise of the team as a whole and the higher team cohesion in order to achieve the overall team is greater than the power of the individual and the effect. (1) The teaching team goals clear. "Silk Road youth" repertoire practice teaching, the entire teaching team's goal is to cultivate the application of talent to enhance the level of practical teaching, each sub-teaching team has its own clear practical teaching objectives, such as dance teaching team is to improve the students dance Practice performance ability, in order to cultivate professional talents of dance lay a good foundation. Under this goal, the teaching team members to the heart of a thought, strength to a place to make. (2) The leader of the teaching team to take the lead. Each teaching team leader is the professional business level is high, teaching ability, and high moral character, good conduct of the backbone, they are not only solid theory, practical experience, and good at taking the lead role, have a certain appeal and Influence, can well drive the operation of the entire teaching team. For example, the music teaching team leader music director, not only professional first-class, but also in the teaching team, has a strong influence and appeal, has been rushing in the "Silk Road youth" repertoire practice teaching first line, driven and encouraged with this teaching team.

The teaching team is becoming more and more standardized. The efficient operation of the teaching team is inseparable from the normative management. From the "Peace Trilogy" ("Soup", "Sakura Soul" "Peace Ode") to "Silk Road Youth", in the repertoire of practical teaching, the art of exploration of a teaching team standardized management of the road. From the "Silk Road youth" large teaching team, the establishment of multi-agent linkage of the full management mechanism: (1) a special management agency. College of the performance of the office, the practice of teaching management center, responsible for the practice of teaching management and large-scale activities, clear the "Silk Road youth" teaching team's goals, to determine the division of the sub-teaching team, tasks, and is responsible for teaching team and Sub-teaching team between the upload and release and sub-teaching team between the coordination and communication; (2) the establishment of an effective accountability mechanism. The executive office and the practice teaching management center are the main management units. The Academic Affairs Office and the Student Office are the management units, the clear management scope and responsibilities, and the establishment of practical teaching and teaching team management rules and regulations. From the "Silk Road youth" repertoire of the beginning to the end of the performance, the establishment of the whole process of management mechanism: prior to the clear division of the various teaching team, according to professional, the task of writing "Silk Road youth" repertoire practice teaching program, the development of classroom teaching plan and the specific norms of the lesson plan, the specific implementation of each team to each teacher, and the competent departments of lectures, records of the record; afterwards, there are repertoire of practical teaching results and teaching team summary and team personal summary.

In order to improve the teaching effectiveness of the teaching team, the establishment of a 
scientific evaluation mechanism: the team by the teaching team to assess the workload of each teacher, contribution, by the competent organization to assess the performance of the teaching team, follow the public, open and impartial principles, combined with qualitative, incentive-based, team rewards and personal rewards.

"Silk Road Youth" Repertoire Research Team Building. Project construction as a link to carry out scientific research team construction is an important way to build high-level scientific research team, "Silk Road youth" as a large original repertoire to promote scientific research team building. Hospital leaders put forward the "big repertoire to be included in the research into the" requirements. In the previous "peace song" repertoire practice teaching to carry out the school-based research project bidding work, and finally there are nine project set up a corresponding research team. On the basis of this experience, through the "Silk Road youth" repertoire practice teaching, to further improve the school-based research work, the majority of teachers research enthusiasm, a total of 45 projects, set up 45 research team, covering the various faculties and the main sector, almost all involved in all professional, led the school's research and development work. Around the "Silk Road youth", scientific research topics have macro research and micro-research and theoretical research and applied research, there are repertoire connotation excavation and drama extension study, teaching research and management research, personnel training research and teacher ability research, etc.

Each research team consists of 3-6 people, by the subject of research experience teachers or professors, associate professors as leaders; research group members have the same direction of research, some research complement each other, to encourage interdisciplinary professional cross research, encourage In order to better develop students' scientific research ability, require each research team to add 1-2 students, so that students in the scientific research team in advance to experience the atmosphere of scientific research. In order to better develop the scientific research ability of the students, cultivate scientific research interests and awareness.

In this process, the individual research team in the individual ability of teachers has been greatly improved, more standardized management.

Teachers' scientific research ability has improved significantly. A scientific research workers in the research team, generally than the singles will make significant progress, can enhance its core competitiveness, not only for the team to contribute, and personal interests are guaranteed, to understand the process of cooperation with each other to promote, A better understanding of the significance of scientific research work [3]. Through the "Silk Road youth" related research, team leader, experienced teachers, young teachers will understand the significance of scientific research, learn how to engage in scientific research; teachers through seminars, exchanges will produce new ideas and good. The idea of "Silk Road Youth" involves a wide range of topics, and closely linked with the specific practice of our hospital, teachers can choose their own interests and expertise, in accordance with their own professional and expertise, in-depth the study. Teachers in the "Silk Road youth" research team, in order to a common goal, a clear division of labor, mutual help, so that teachers of scientific research capacity significantly improved.

Teachers' research team system is improving. The construction of scientific research team cannot be separated from the protection of the system. In addition to the relevant scientific research management regulations and methods, but also to "Silk Road youth" research as an opportunity to develop "scientific research team construction and management requirements" "scientific research team management incentives", the purpose is to fill the scientific research team system of the blank, so that scientific research team construction and management more standardized and scientific, play the biggest benefits of scientific research team.

\section{Conclusion and Discussion}

The construction of teaching teams and research teams in applied colleges and universities must aim at cultivating the talents needed to serve the regional economic development, and promote the construction of teaching team and scientific research team by exploring the means and methods suitable for their own characteristics. From the great art "Silk Road youth" repertoire practice 
teaching team and research team to build the useful practices, we get revelation, as an applied university, in order to do a good job both construction and we must pay attention to the following:

Teaching team and research team building is long-term. The art of "Silk Road youth" related to the teaching team and research team is not the end of the practice of teaching on the end of the disintegration, but as far as possible within a certain range to ensure its stability, so the team through the "Silk Road youth" repertoire practice exercise, help each other mutual assistance, joint efforts, research and exchange, resulting in a tacit understanding, not only successfully and efficiently complete the corresponding teaching, research objectives and tasks, but also in the future of other teaching and research tasks to better play teamwork with the greatest benefits.

Teaching team and scientific research team construction is normative. The reason why the team can play a team spirit, gather the wisdom of the group, to achieve the best results, because there is a corresponding mechanism, the system to ensure that the team's operation is normal, scientific and effective.

Teaching team and research team building are across. This cross, one is the team within the professional cross, so that both can expand the knowledge to make up for the shortcomings of teachers and shortcomings; and can facilitate cross-professional research, learn from each other. Second, the teaching team and research team cross, teaching team and research team personnel can be crossed, because the teaching and research as the birds of the wings, the car two rounds to complement each other, one forward, from the actual teaching can tap the potential research the direction of the subject, the results of scientific research can be used to guide the teaching, this cross is more conducive to the integration of production and research.

\section{References}

[1] Ministry of Education. Ministry of Education on the undergraduate colleges to the application of the type of guidance[Z].

[2] Lin Yan.Study on Problems and Countermeasures of Scientific Research Team Construction in Applied Universities[J]. Journal of Taiyuan Urban Vocational College, 2017 (5) (in Chinese with English abstract)

[3] Ma Yugang. Local colleges and universities research team construction research[J]. Higher finance and economics education, 2015 (4) 